\title{
Indicadores de saúde e testagem para a COVID-19
}

Carolina Gomes Coelho ${ }^{1}$

Flávia Bulegon Pilecco ${ }^{2}$

1 Professora do Departamento de Medicina Preventiva e Social da Universidade Federal de Minas Gerais (UFMG). Graduação e mestrado em Nutrição pela Universidade Federal de Viçosa (UFV). Doutorado em Saúde Pública pela UFMG.

2 Professora do Departamento de Medicina Preventiva e Social da Universidade Federal de Minas Gerais (UFMG). Graduação em Biomedicina pela Universidade Federal de Ciências da Saúde de Porto Alegre (UFCSPA). Mestrado e doutorado em Epidemiologia pela Universidade Federal do Rio Grande do Sul (UFRGS).

COELHO, C. G.; PILECCO, F. B. Indicadores de saúde e testagem para a Covid-19. In: BARRETO, M. L.; PINTO JUNIOR, E. P.; ARAGÃO, E.; BARRAL-NETTO, M. (org.). Construção de conhecimento no curso da pandemia de COVID-19: aspectos biomédicos, clínico-assistenciais, epidemiológicos e sociais. Salvador: Edufba, 2020. v. 2. DOI: https://doi.org/10.9771/9786556300757.004 


\section{Importância dos indicadores de saúde para o planejamento em saúde e combate à COVID-19}

Um indicador de saúde pode ser definido como uma variável mensurada para monitorar o progresso ou avaliar o que funciona e o que não funciona quanto às ações relacionadas à saúde. (MURRAY, 2007) Os indicadores de saúde, portanto, possuem uma importância fundamental para a saúde pública e o surgimento de novos problemas em saúde, como é o caso da COVID-19, só reforça tal fato. A disponibilidade de indicadores de saúde de boa qualidade é essencial para se conhecer essa nova doença, sua dinâmica de transmissão e seus impactos na saúde e na vida das populações. A partir deles, é possível traçar um plano de ação em saúde e adotar estratégias com vistas a controlar o avanço da epidemia de forma eficaz.

\section{Indicadores de saúde na COVID-19}

Alguns dos principais indicadores utilizados no monitoramento da pandemia da COVID-19 serão descritos a seguir no presente tópico. 


\section{Incidência acumulada}

A incidência é considerada uma medida da intensidade com a qual a doença ou agravo ocorre na população. Por meio do monitoramento do número de novos casos, tal medida reflete a dinâmica da ocorrência de determinada morbidade. É um indicador muito relevante na formulação, implementação e avaliação de estratégias de prevenção e controle de morbidades. (MOTA; KERR, 2011)

A medida de incidência acumulada pode ser definida como a relação entre o número de casos novos de uma doença ou agravo e a população exposta ao risco de desenvolver tal doença ou agravo, em um determinado intervalo de tempo e local. (MOTA; KERR, 2011) A incidência acumulada se constitui em uma medida típica do risco potencial de adoecer ou sofrer agravo.

Em 26 de setembro de 2020, a incidência acumulada mundial do novo coronavírus era de 4,2 casos/1 mil habitantes. Na mesma data, o Qatar ocupava o primeiro lugar na incidência acumulada de casos, alcançando a marca de 43 casos/1 mil habitantes. É interessante observar a amplitude dos dados de incidência acumulada: enquanto países como Brasil, Chile, Israel, Peru e Estados Unidos estavam entre os 10 países com maior incidência acumulada com valores por volta de 23 casos/1 mil habitantes, países como China, Taiwan e Tailândia apresentavam valores abaixo de 0,1 caso/1 mil habitantes. (OUR WORLD IN DATA, 2020)

\section{Mortalidade}

As medidas de mortalidade são consideradas indicadores das condições de saúde de uma população, já que são úteis para avaliar o nível de saúde e, consequentemente, indicar medidas preventivas e de controle abrangentes que tenham como objetivo melhorar o estado de saúde dos indivíduos e populações. (CARVALHO; BUSS, 2012; GORDIS, 2017; MOTA; KERR, 2011) Conhecer a mortalidade de uma população pode ainda apontar com precisão diferenças 
no risco de morte por doenças entre pessoas em diferentes áreas geográficas e subgrupos da população. (GORDIS, 2017)

A taxa de mortalidade "é a proporção entre a frequência absoluta de óbitos e o número de indivíduos expostos ao risco de morrer, no mesmo período de referência e no mesmo local". (MOTA; KERR, 2011, p. 105) A taxa de mortalidade para a COVID-19 é, portanto, o resultado da divisão do número absoluto de óbitos por COVID-19 pelo número de indivíduos expostos ao risco de morrer, incluindo nesse denominador os que têm e os que não têm a COVID-19. Assim, no presente capítulo, consideramos como denominador da taxa de mortalidade por COVID-19 toda a população estimada de determinado local no ano de 2020.

A mortalidade mundial por COVID-19 era de 127 mortes/ milhão de habitantes em 26 de setembro de 2020, e San Marino ocupava o primeiro lugar com 1.237 mortes/milhão de habitantes. Países como Espanha, Chile, Equador, Brasil e Reino Unido ocupavam o ranking dos 10 países com maior mortalidade na mesma data - com taxa de mortalidade em torno de 650 mortes/milhão de habitantes -, ao passo que Nova Zelândia, Singapura, Malásia e China apresentavam valores abaixo de 10 mortes/milhão de habitantes. (OUR WORLD IN DATA, 2020)

\section{Letalidade}

A letalidade expressa a gravidade de uma doença ou agravo, indicando "o maior ou menor poder que uma doença ou agravo tem de provocar a morte das pessoas acometidas pela doença ou que sofreram agravos à saúde”. (MOTA; KERR, 2011, p. 110) Assim, a taxa de letalidade é a proporção entre a frequência absoluta de óbitos por determinada doença ou agravo e o número de indivíduos com a determinada doença ou agravo. Diferentemente da mortalidade, o denominador da taxa de letalidade abrange somente os que já possuem a referida morbidade. (GORDIS, 2017; MOTA; KERR, 2011) 
Existe, na literatura, uma discussão acerca das terminologias que envolvem a letalidade para a COVID-19 - e é preciso compreendê-las diante do cenário atual. Alguns autores classificam a letalidade em aparente e plausível. A case-fatality rate, traduzida como "caso-fatalidade" ou "letalidade aparente", é definida como a "proporção de casos diagnosticados de uma condição especificada que são fatais dentro de um tempo especificado”. (GREWELLE; DE LEO, 2020; PORTA, 2008) Já a infection fatality rate, traduzida como "letalidade plausível”, representa a proporção de óbitos entre todos os indivíduos infectados por uma determinada condição. (GREWELLE; DE LEO, 2020; IOANNIDIS, 2020) Nota-se, portanto, que enquanto a letalidade aparente considera somente os casos diagnosticados em seu denominador, a letalidade plausível inclui todos os infectados pela doença em questão: casos diagnosticados ou não, aqueles assintomáticos, os que não foram testados e os que não possuem o diagnóstico da doença. Sua estimação é, portanto, bastante complexa e possível apenas em casos específicos. Para a COVID-19, a notória subestimação de casos, decorrente também da testagem insuficiente, se configura em uma justificativa para o uso do termo "letalidade aparente", ou seus sinônimos. Dessa forma, no presente capítulo, utilizaremos o termo "letalidade" como sinônimo de "letalidade aparente", com vistas a facilitar a leitura do texto.

Apesar da dificuldade na estimação, estudo realizado em pequeno contingente populacional indica que a letalidade plausível pelo novo coronavírus situa-se em torno de 1\%. (GREWELLE; DE LEO, 2020) Tal valor é semelhante à estimativa feita para o Brasil pelo Imperial College COVID-19 Response Team, que varia de $0,7 \%$ a 1,2\%3 (MELLAN et al., 2020), e pelo estudo de Evolução da

3 As estimativas de Infection Fatality Rate esperadas em diferentes estados brasileiros foram derivadas de estimativas publicadas anteriormente de padrões observados da América Latina, juntamente com as estimativas 
Prevalência de Infecção por COVID-19 (EPICOVID-19), que concluiu que essa letalidade é de 1\%. (HALLAL et al., 2020) Assim, embora o vírus SARS-CoV-2 seja altamente transmissível, estima-se que sua letalidade seja menor que a da Síndrome Respiratória Aguda Grave (SARS) (9,5\%) e da Síndrome Respiratória do Oriente Médio (MERS) (34,4\%), mas superior à da influenza (0,1\%). (RAJGOR et al., 2020)

Considerando-se apenas os casos diagnosticados, a letalidade no mundo em 26 de setembro de 2020 era de 3,0\%, variando de menos de 1\%, em países como Singapura, Emirados Árabes Unidos, Islândia e Israel, a acima de 7\% em países como o Equador, Bélgica, México e Reino Unido, 11,7\% na Itália, e chegando a 28,9\% no Iêmen. (OUR WORLD IN DATA, 2020)

\section{Taxa de positividade}

A proporção de testes positivos dentre os testes realizados, também chamada de taxa de positividade, é uma boa métrica do quão amplamente os países estão testando para determinada doença. Proporções menores de testes positivos indicam um rastreamento mais amplo, que não se restringe aos sintomáticos ou às pessoas cujo diagnóstico é fortemente previsível. (OUR WORLD IN DATA, 2020) Esse indicador fornece uma estimativa da sensibilidade do sistema em identificar os casos positivos.

A Organização Mundial da Saúde (OMS) recomenda que, para um país iniciar a flexibilização da quarentena e do distanciamento

da transmissibilidade do vírus (o número básico de reprodução, Rt) derivadas de cenários europeus e de estimativas da gravidade da doença derivadas da epidemia chinesa, e subsequentemente modificada para corresponder aos dados emergentes da epidemia no Reino Unido. Além disso, modificou-se tais estimativas de Infection Fatality Rate para abranger a heterogeneidade substancial que se espera observar com relação aos sistemas de saúde nos estados brasileiros, devido à variação na qualidade e capacidade da assistência médica. Mais detalhes em Grassly e demais autores (2020). 
social, a proporção de testes positivos deve ser inferior a 5\%, por pelo menos 14 dias. (WORLD HEALTH ORGANIZATION, 2020a) Assim, uma baixa taxa de positividade indicaria que um país ou região alcançou a capacidade ideal de testagem para determinar a extensão de sua epidemia e ser capaz de formular políticas de reabertura da economia de forma adequada. (JOHNS HOPKINS CORONAVIRUS RESOURCE CENTER, 2020)

Alguns países como Coréia do Sul, Austrália, Canadá e vários países europeus apresentavam a taxa de positividade inferior a $1 \%$ no final de setembro de 2020 , ou seja, eles realizavam centenas ou até milhares de testes para cada caso que encontravam. Outros países como Argentina, México, Bolívia, Paraguai e Brasil apresentavam uma taxa de positividade superior a $20 \%$, ou seja, eles realizavam cinco ou menos testes para cada caso confirmado. (OUR WORLD IN DATA, 2020)

\section{Fatores que influenciam os indicadores de saúde utilizados no monitoramento da COVID-19}

Em geral, as comparações intra e entre países em relação à evolução e gravidade da pandemia têm sido feitas principalmente com base no número absoluto de casos, além de indicadores como incidência acumulada, mortalidade e letalidade, que utilizam o número de óbitos e de doentes em sua construção.

Undela e Gudi (2020) afirmam que as discrepâncias observadas nas comparações de diferentes locais são em maior parte influenciadas por 5D’s: demografia, definição de mortes relacionadas à COVID-19, diferenças nas estratégias de testagem, diferenças nos sistemas de saúde e dissimilaridade nas estratégias preventivas. Esses determinantes podem variar entre países, dentro de um mesmo país e até em um mesmo local, em diferentes 
momentos. Além disso, outros elementos, como o momento epidêmico pelo qual a localidade está passando, precisam ser considerados. (GIANICOLO et al., 2020)

A seguir, problematizaremos brevemente as mudanças nos critérios para definir casos e óbitos, a estrutura do sistema de saúde local e as diferentes estratégias de testagem.

\section{Mudanças nos critérios para definir \\ caso e óbito por COVID-19}

As mudanças nos critérios para definir caso e óbito por COVID-19 são comuns, visto o surgimento recente da doença e os consequentes avanços constantes para aprimorar seu diagnóstico.

Um exemplo de como as mudanças na definição de óbito podem impactar nos indicadores em saúde aconteceu no município do Rio de Janeiro. No dia 27 maio de 2020, houve uma revisão da definição de óbito pelo novo coronavírus, que passou a ser restrita aos casos cuja confirmação foi feita laboratorialmente, em detrimento daqueles com diagnóstico puramente clínico. (MUDANÇA...., 2020) Consequentemente, os indicadores de mortalidade e letalidade sofreram uma aparente queda em relação ao período anterior.

Outro exemplo ocorreu quando o próprio Ministério da Saúde brasileiro mudou os critérios para definição de caso diagnosticado por COVID-19, ampliando o diagnóstico clínico e incluindo aquele por imagem. Tais mudanças podem ocorrer conforme o conhecimento sobre a COVID-19 se amplifica e é importante que sejam consideradas quando indicadores de saúde forem analisados e interpretados. (BRASIL., 2020d)

\section{Estrutura do sistema de saúde local}

A estrutura dos sistemas de saúde dos países possui um papel crucial na dinâmica de transmissão e controle da COVID-19. As medidas de 
saúde pública tomadas para gerenciar a epidemia contam com as capacidades nacionais e regionais existentes dos sistemas de saúde para prevenir, detectar, verificar, avaliar e responder às emergências de saúde pública.

Recomendações para adequações dessa capacidade de resposta estão presentes no Regulamento Sanitário Internacional proposto pela Organização das Nações Unidas (ONU) e pelo Banco Mundial (BM) (GLOBAL PREPAREDNESS MONITORING BOARD, 2019), em vigor desde 2007. No entanto, ao avaliar a capacidade de segurança sanitária no contexto da epidemia de COVID-19 em 182 países, Kandel e demais autores (2020) verificaram uma ampla variação quanto à capacidade de prevenir, detectar e responder a surtos em geral. Apesar de metade desses países possuírem fortes capacidades de prontidão operacional, ainda são escassas as avaliações que buscam compreender as capacidades nacionais de prontidão específicas para a COVID-19.

Como parte dos sistemas de saúde e diante do cenário de pandemia, é importante ressaltar o papel crucial da vigilância epidemiológica, que se caracteriza pela coleta, análise, interpretação e disseminação sistemática e contínua de dados relativos a um evento relacionado à saúde com o intuito de planejar ações efetivas no "controle prevenção" do evento em questão. Dessa forma, a vigilância epidemiológica é uma parte crítica da prática de saúde pública, já que a qualidade dos dados epidemiológicos e indicadores de saúde é crucial para se obter a informação acurada e para que se defina um panorama real do problema e as consequentes ações em saúde e intervenções necessárias no combate à COVID-19. (IBRAHIM, 2020) Mais detalhes sobre a atuação e papel da vigilância em saúde em cenário de pandemia de COVID-19 podem ser vistos em outros capítulos da presente obra. 


\section{Estratégias de testagem}

Apesar da importância da testagem para o entendimento do comportamento e da magnitude de uma doença, em especial quando causada por um novo vírus como o SARS-CoV-2, nota-se que as táticas adotadas pelos países variam enormemente, e não é incomum que tais estratégias sejam distintas a depender da fase da epidemia. (RED ARGENTINA PÚBLICA DE EVALUACIÓN DE TECNOLOGÍAS SANITARIAS, 2020) Consequentemente, as diferenças nos protocolos e nos recursos alocados para testagem resultam em indicadores de saúde muito variados. (ONDER; REZZA; BRUSAFERRO, 2020)

É importante mencionar que os dois tipos de testes disponíveis para a COVID-19 são: i) os de Reação em Cadeia de Polimerase por Transcriptase Reversa (RT-PCR), que permitem identificar pessoas infectadas; e ii) os sorológicos, que detectam pessoas que já tiveram contato com o vírus e desenvolveram anticorpos. (ONDER; REZZA; BRUSAFERRO, 2020) Nas informações a seguir sobre as estratégias de testagem nos países, o tipo de teste realizado foi mencionado quando a fonte de informações do país fornecia esse dado. Além disso, a fonte de dados sobre testagem utilizada no presente capítulo (OUR WORLD IN DATA, 2020) inclui somente os dados de testagem por RT-PCR, em consonância com as recomendações da OMS para diagnóstico de infecção ativa por SARS-CoV-2. É importante ressaltar ainda que as informações foram coletadas até setembro de 2020 , e após esse período mudanças podem ter ocorrido nas estratégias de testagem.

\section{Países com estratégias de testagem mais amplas}

Coreia do Sul, Taiwan, Hong Kong, China, Emirados Árabes Unidos e Barein são exemplos de países que passaram por experiências anteriores de epidemias causadas por vírus respiratórios, como a MERS e SARS, e que adotaram estratégias mais amplas de testagem para COVID-19. 
A Coréia do Sul adotou precocemente medidas de distanciamento social e de testagem abrangente para o novo coronavírus (RICHTERICH, 2020), incluindo a testagem por drive-thru, o que culminou na realização de 300 mil testes nas semanas posteriores à identificação do primeiro caso de COVID-19. (COHEN; KUPFERSCHMIDT, 2020; KOREAN SOCIETY OF INFECTIOUS DISEASES et al., 2020) Tal abordagem contribuiu para lidar com o avanço da pandemia no país.

Taiwan adotou um sistema de vigilância abrangente e investiu na ampliação da capacidade laboratorial para o diagnóstico precoce da doença, sendo capaz de, ao final de fevereiro de 2020, realizar 3 mil testes de diagnóstico molecular para SARS-CoV-2 por dia. A estratégia de testagem incluiu busca ativa, rastreamento e retestagem para COVID-19 de indivíduos sintomáticos graves que tiveram resultados negativos para influenza, e a testagem dos contatos de casos confirmados de COVID-19. (CHANG; CHIU, 2020; CHENG; LI; YANG, 2020; WANG; NG; BROOK, 2020)

A cidade semiautônoma de Hong Kong também implementou uma ampla testagem para COVID-19 em indivíduos sintomáticos, com rastreamento e isolamento dos contatos. No âmbito hospitalar, apenas os pacientes com pneumonia sem diagnóstico microbiológico eram testados. Mas, com o avançar da epidemia, foram incluídos todos os pacientes internados com pneumonia e uma amostra de pacientes ambulatoriais e de emergência, totalizando cerca de 1.500 testes por dia. (BOSELEY, 2020; LEGIDO-QUIGLEY et al., 2020)

A China é um caso peculiar de país que optou por uma estratégia ampla de testagem, mas focada em uma província (Hubei). Inicialmente, adotou-se um princípio de identificação, isolamento, diagnóstico e tratamento precoces e, no final de fevereiro de 2020 , a testagem por RT-PCR se tornou menos restrita, abrangendo pessoas com baixa suspeita de COVID-19. Em meados de maio, um pequeno surto de COVID-19 na cidade de Wuhan fez com que as autoridades chinesas planejassem testar todos os 11 milhões de 
habitantes dessa localidade em 10 dias, com vistas a impedir o avanço do surto. (WHO, 2020b) No início de junho de 2020, foi anunciada a conclusão desse programa de testagem em massa, com 10,9 milhões de habitantes testados. Tal feito só foi possível devido ao aumento da capacidade de testagem em 300\%, testagem domiciliar e testagem em pool. (REALITY CHECK TEAM, 2020)

Enfim, fechando o grupo dos países asiáticos que já vivenciaram epidemias causadas por vírus respiratórios, Emirados Árabes Unidos e Bahrein se destacam ao liderarem o ranking de testagem por habitantes - ambos já realizaram mais de 800 testes para cada mil habitantes até setembro de 2020. (OUR WORLD IN DATA, 2020) Mesmo com essa elevada taxa de testagem, esses países apresentaram um aumento no número diário de casos de COVID-19 no mesmo período - o que pode indicar uma falha na adoção conjugada de outras medidas de mitigação para o controle do COVID-19.

No continente europeu, a Alemanha se destaca por ter adotado uma estratégia de testagem que abrange suspeitos com sintomas leves e os jovens, realizada de forma descentralizada e seu protocolo foi elaborado ainda em janeiro de 2020. (STAFFORD, 2020) A Islândia também se destaca no combate à pandemia, obtendo êxito em grande parte devido à sua estratégia de testagem. Enquanto o sistema de saúde islandês focou na realização de testes sintomáticos graves, contatos de casos confirmados e sintomáticos que retornaram de áreas de risco, indivíduos com poucos ou nenhum sintoma, que não estavam em quarentena e nem foram testados pelo outro sistema foram testados de forma voluntária e gratuita pela empresa biofarmacêutica deCODE Genetics. (GUDBJARTSSON et al., 2020) Dessa forma, até o final de setembro de 2020, o país havia testado em torno de 37\% de sua população. (OUR WORLD IN DATA, 2020)

Fechando o grupo de países com estratégias mais amplas de testagem, a Nova Zelândia se destaca como um caso de sucesso 
no combate ao novo coronavírus. Até meados de junho de 2020, mais de 310 mil pessoas já haviam sido testadas (de um total de 5 milhões de habitantes). (COUSINS, 2020) Os testes foram direcionados a indivíduos sintomáticos, com rastreamento e isolamento de contatos próximos e casuais. (GUNIA, 2020) Além disso, com o curso da pandemia, a testagem foi ampliada para assintomáticos dos seguintes grupos: trabalhadores da saúde; trabalhadores das áreas de turismo, transporte e de companhias aéreas; pessoas que trabalham nas fronteiras e seus contatos; e pessoas com pior prognóstico devido a condições preexistentes e que residem na área de Auckland. (COUSINS, 2020; NEW ZEALAND MINISTRY OF HEALTH, 2020)

\section{Países com estratégias de testagem mais restritas}

Outros países, seja em função da fase da epidemia, de restrições orçamentárias, do tamanho populacional ou do projeto de governo em exercício, adotaram estratégias mais conservadoras de testagem. Nesses cenários, os critérios para qualificar um indivíduo para a testagem incluem apresentar sintomas graves, contato prévio com um caso confirmado de COVID-19, pertencer a um grupo de "alto risco", ou a combinação desses e de outros critérios. (RICHTERICH, 2020)

No Japão, país que passou pela epidemia de influenza H1N1 em 2009, foi adotada a testagem de todos os casos suspeitos independentemente de seu histórico de viagens, além de outras medidas. No entanto, apesar da boa capacidade de testagem instalada no país, há relatos de que somente sintomáticos mais graves foram testados e que o número de testes realizados equivale à metade da capacidade diária do país (LEGIDO-QUIGLEY et al., 2020; TANNE, 2020), fator que pode ter contribuído pra que o Japão esteja continuamente no ranking dos 50 países com maior número absoluto de casos de COVID-19. 
Na Europa, países como Itália, Espanha, Portugal, França e Reino Unido adotaram inicialmente estratégias mais restritivas de testagem, focadas em sintomáticos graves. No entanto, com o avançar da epidemia e com a expansão da capacidade de testagem, tais países ampliaram os critérios, passando a incluir testagem em sintomáticos leves e outras populações em maior risco de contrair o vírus, como profissionais de saúde.

Os Estados Unidos postergaram o início da testagem na população e não atingiram o número necessário de testes diários para monitorar adequadamente a epidemia até junho de 2020. O público prioritário foi composto por pacientes hospitalizados e profissionais de saúde, mas não existem dados completos em nível individual que informem os critérios que determinam quem será testado. Existem indícios de que essa (falta de) estratégia parece estar sendo abandonada em prol da adoção de uma política mais ampla de rastreio de contatos e isolamento, visando reduzir o impacto econômico da pandemia a longo prazo, com um investimento de 25 bilhões de dólares. (SCHNEIDER, 2020)

Em relação aos países de baixa e média renda, na Índia, que em setembro de 2020 era o segundo país com maior número absoluto de casos, a política de testagem incluía todos os sintomáticos, indivíduos com histórico de viagens internacionais nos últimos 14 dias, os que tiveram contato com casos confirmados laboratorialmente, os que estivessem em cidades foco da epidemia, profissionais de saúde ou trabalhadores da linha de frente na mitigação da COVID-19, e migrantes e pessoas que retornaram à Índia. Adicionalmente, deveriam ser testados todos os pacientes com SRAG e todas as pessoas hospitalizadas que desenvolveram sintomas. (INDIAN COUNCIL OF MEDICAL RESEARCH, 2020)

O Afeganistão não possui dados disponíveis de testagem atuais, mas merece atenção por encontrar-se empobrecido, devastado pela guerra e por ter um grande número de pessoas 
deslocadas por conflitos e desastres naturais. (SHAH et al., 2020) Além de características socioeconômicas, culturais e do próprio sistema de saúde, ainda em estruturação, apenas um laboratório central estava realizando testes para a COVID-19, com capacidade máxima de 50 exames por dia e custo de US\$1.600 por kit de diagnóstico. Com isso, ocorrem importantes atrasos no tratamento e isolamento de pacientes, especialmente em áreas mais distantes da capital. (SHAH et al., 2020) Diante desse cenário e da reduzida capacidade de testagem, é possível que o declínio no número de novos casos diários observado até o final de setembro de 2020 seja fruto de subestimação.

Alguns países da América Latina também têm adotado abordagens mais restritivas de testagem. No México, são testados apenas casos graves e os casos suspeitos são monitorados. Essa estratégia é complementada por um sistema sentinela de monitoramento dos casos de SRAG para identificação daqueles causados por SARS-CoV-2. (MARTÍNEZ-ANAYA; RAMOS-CERVANTES; VIDALTAMAYO, 2020) $\mathrm{Na}$ Argentina, apesar das medidas mais restritivas de quarentena e distanciamento social, são testados apenas os casos suspeitos. Todos os profissionais de saúde com febre ou pelo menos dois outros sintomas também devem ser testados por RT-PCR. (RED ARGENTINA PÚBLICA DE EVALUACIÓN DE TECNOLOGÍAS SANITARIAS, 2020)

O Brasil se destaca no grupo de países que menos testa - por volta de 30 testes para cada mil habitantes em setembro de 2020 . O Ministério da Saúde recomenda a testagem de sintomáticos que fazem parte dos seguintes grupos: profissionais de saúde e segurança pública em atividade; pessoas residentes no mesmo domicílio de um profissional de saúde ou segurança pública em atividade; pessoa com idade igual ou superior a 60 anos; portadores de condições de risco para complicações da COVID-19; e população economicamente ativa. (BRASIL, 2020c, 2020d) Essa seleção de sintomáticos faz com que o país apresente uma taxa de positividade 
de testagem próxima a $40 \%$, testando cerca de duas vezes menos que a Índia, e ocupando o $66^{\circ}$ lugar dentre os 100 países com dados de testagem disponíveis em setembro de 2020. No mesmo período, em comparação aos Emirados Árabes Unidos - país com maior número de testes por habitantes do mundo -, o Brasil testava cerca de 26 vezes menos. (OUR WORLD IN DATA, 2020)

\section{Impacto das políticas de testagem para COVID-19 na estimativa de indicadores de saúde}

A depender das estratégias de testagem adotadas, do número de testes aplicados e do direcionamento de testes para indivíduos com quadro clínico mais ou menos grave, os indicadores em saúde podem ou não refletir o número real de casos e mortes por COVID-19 em um determinado país. (LACHMANN et al., 2020; RAJGOR et al., 2020) Vários estudos têm demonstrado que a subestimação do número de casos de COVID-19 é um problema mundial, e que a estimativa do número real de infectados seria, em média, 2 a 13 vezes maior que o número de casos notificados. (LACHMANN et al., 2020; MAUGERI et al., 2020; RICHTERICH, 2020; WU et al., 2020) No Brasil, um estudo de base populacional desenvolvido no Rio Grande do Sul corroborou com essa afirmativa, indicando que, para cada caso diagnosticado, existem 12 que não foram identificados e notificados. (UNIVERSIDADE FEDERAL DE PELOTAS, 2020)

É importante lembrar que o tipo de teste realizado, o período de aplicação do teste - dias pós-contágio -, sua forma de execução e o erro inerente ao instrumento - de acordo com sua sensibilidade e especificidade -, também podem contribuir para a subestimação do número de casos de COVID-19. 
A seguir, o impacto das estratégias de testagem será abordado diante das peculiaridades de cada indicador de saúde.

\section{Incidência acumulada}

A incidência de um país ou região pode estar aparentemente mais elevada, não por um aumento real no número de casos, mas sim devido a uma maior taxa de testagem: quanto mais se testa, maior a probabilidade de se diagnosticar os casos de COVID-19. (COELHO et al., 2020) Uma forma de dimensionar se o número de testes realizados é suficiente para monitorar a incidência da COVID-19 é através da taxa de positividade. A OMS indica um valor abaixo de $5 \%$ como o ideal para que um país ou região seja capaz de determinar a extensão de sua epidemia e de estabelecer políticas de reabertura da economia de forma apropriada. (JOHNS HOPKINS CORONAVIRUS RESOURCE CENTER, 2020)

Além disso, ao analisarmos a incidência acumulada, é de extrema relevância considerar o momento da pandemia em que um país ou região se encontra ao se comparar incidências de COVID19. Por exemplo, no início de junho de 2020, a Itália apresentava incidência acumulada 33\% maior que a do Brasil. Nesse período, enquanto o Brasil se encontrava em trajetória ascendente na curva do número de casos - média de 27 mil por dia -, a Itália estava em trajetória descendente há mais de 60 dias - média de 350 casos por dia. (OUR WORLD IN DATA, 2020; WORLDOMETERS, 2020) Assim, a comparação de tais incidências deve ser feita com parcimônia, e deve considerar o estágio da pandemia no qual os países encontram - tal recomendação se aplica também à comparação de outros indicadores de saúde entre países ou regiões.

Para amenizar, ao menos parcialmente, o efeito das diferentes estratégias de testagem adotadas pelos países, alguns autores sugerem o uso de outros indicadores, além da curva epidêmica, que forneçam uma ideia mais fidedigna da tendência de aumento 
ou diminuição da incidência da doença. Um exemplo é o tempo de duplicação (tempo necessário para dobrar a incidência cumulativa). Um aumento no tempo de duplicação indica desaceleração da epidemia e que as políticas públicas de contenção adotadas estão surtindo efeito. (BETENSKY; FENG, 2020) Tal indicador é relevante para monitorar o crescimento da epidemia mesmo que a testagem seja realizada em um grupo restrito pois, se as estratégias de testagem se mantiverem constantes, a variação do tempo de duplicação indicará o crescimento ou a diminuição da doença. $\mathrm{O}$ número efetivo de reprodução (Rt) também pode ser considerado para acompanhar a evolução da epidemia, uma vez que representa o número de pessoas para o qual uma pessoa infectada transmite o vírus. (LIU et al., 2020) O Rt maior que 1,0 indica que a epidemia está em expansão.

\section{Mortalidade}

É fundamental ressaltar que a subnotificação não atinge apenas os casos por COVID-19, mas também as mortes causadas pela doença. Um dado que corrobora com essa subnotificação é o aumento de $1.035 \%$ nos óbitos por SRAG que ocorreu desde o registro da primeira morte por COVID-19 no Brasil, segundo informações disponibilizadas pelos Cartórios do país, através do Portal da Transparência do Registro Civil. (CARTÓRIOS..., 2020) Mesmo diante das fortes evidências de subnotificação, em 5 de junho de 2020, o Brasil alcançou o primeiro lugar no ranking mundial de novas mortes diárias por milhão de habitantes por COVID-19, ou seja, um óbito por minuto devido à doença. (OUR WORLD IN DATA, 2020)

Outra importante questão reside na dificuldade em diferenciar mortes com a presença de infecção por SARS-CoV-2 de mortes causadas pela infecção por SARS-CoV-2. Na Itália, por exemplo, a grande maioria dos pacientes que morreram e apresentavam COVID-19 tinha uma ou mais comorbidades importantes $-98,8 \%$ 
com pelo menos uma comorbidade, dos quais $48,6 \%$ com três ou mais -, que contribuíram para a sua morte. (BOCCIA; RICCIARDI; IOANNIDIS, 2020)

Apesar da subestimação, estudos vêm apontando que a taxa de mortalidade seria um indicador mais adequado quando comparado à incidência e à letalidade. (HALLAL, 2020; RAJGOR et al., 2020; SPYCHALSKI; BŁAŻYŃSKA-SPYCHALSKA; KOBIELA, 2020) Isso decorre do impacto mais significativo da subestimação no número de casos do que no número de óbitos de COVID-19. (RUDNICKI; PILISZEK, 2020) Além disso, como o denominador da taxa de mortalidade engloba a população total de determinada região ou país, tal indicador seria menos propício a erros se comparado àqueles inteiramente sujeitos à subnotificação, como é o caso da letalidade. (HALLAL, 2020; RAJGOR et al., 2020; SPYCHALSKI; BŁAŻYŃSKA-SPYCHALSKA; KOBIELA, 2020)

Outra medida relacionada à mortalidade que vem sendo utilizada para indicar o avanço da pandemia é o excesso de mortes no período, que utiliza como referência os óbitos observados no mesmo período em anos anteriores. No município de Manaus, por exemplo, registrou-se um aumento de $345 \%$ no número de mortes no período de 19 a 25 de abril de 2020, se comparado aos anos anteriores. (GALINDO; GORTÁZAR, 2020)

\section{Letalidade}

Dentre os indicadores de saúde mencionados neste capítulo, a letalidade é o mais impactado pela subnotificação, já que tanto seu numerador como seu denominador são fortemente influenciados pelas estratégias de testagem. No Brasil, um inquérito de soroprevalência que abrangeu 90 cidades brasileiras e 25.025 participantes estimou que o número de casos de COVID-19, em 13 de maio de 2020 , seria de 760.000 , o que superou em sete vezes o reportado pelos municípios (104.782) no mesmo período. 
Utilizando o número de casos estimado pelo estudo e o número de óbitos acumulados nessa mesma data fornecido pelo Ministério da Saúde, obteve-se uma letalidade de 1,7\% (HALLAL et al., 2020) valor cerca de quatro vezes inferior à letalidade construída com dados oficiais na mesma data (6,9\%). (CONSELHO NACIONAL DE SECRETÁRIOS DE SAÚDE, 2020)

Ao analisar os dados de letalidade de estados brasileiros como São Paulo, Rio de Janeiro, Ceará, Pará e Pernambuco, todos apresentavam, em média, 7\% de letalidade pelo novo coronavírus em $1^{\circ}$ de junho de 2020. (BRASIL, 2020a) Como não há indícios para crer que o vírus seja mais letal em algum local específico, e diante da estimativa global de letalidade plausível de $1 \%$, é possível considerar que a testagem nesses estados é insuficiente para detectar o real número de casos de COVID-19. É provável que tal afirmativa também seja aplicável ao Brasil, já que a letalidade no país, no início de junho de 2020, era de 5,5\%. (OUR WORLD IN DATA, 2020) No Brasil, embora tanto os óbitos quanto os casos de COVID-19 sejam subestimados (BENDAVID et al., 2020), há indícios de que essa subestimação impacte significativamente mais nos primeiros do que nos últimos. (RUDNICKI; PILISZEK, 2020)

O caso da Itália é emblemático para ilustrar como mudanças nos critérios de testagem podem impactar na letalidade. Apesar de inicialmente testar sintomáticos e assintomáticos, no final de fevereiro, os testes passaram a ser prioritariamente dirigidos a sintomáticos graves para a COVID-19. Tal mudança impactou em aumento na taxa de letalidade, já que os indivíduos com quadros mais leves da doença não eram mais testados. Assim, o indicador passou de 3,1\%, em 24 de fevereiro de 2020, para 13,5\%, em 17 de março de 2020. (ONDER; REZZA; BRUSAFERRO, 2020; UNDELA; GUDI, 2020) Outro estudo que indica esse impacto da testagem na estimativa de letalidade através de simulação estimou que, caso fossem testados $50 \%$ dos pacientes sintomáticos não hospitalizados, 
a letalidade seria de $5,3 \%$. Tal letalidade poderia variar de $0,4 \%$, se fosse realizado rastreamento intensivo de contatos e testagem de pessoas não hospitalizadas, a $10,5 \%$, se o teste fosse restrito a pacientes hospitalizados. (MICHAELS; STEVENSON, 2020)

É fundamental considerar ainda que a letalidade também sofre influência de aspectos da organização do sistema de saúde que vão para além da testagem, como a eficiência na notificação de casos e óbitos, a capacitação regular de trabalhadores da saúde, a capacidade do sistema de saúde em assistir adequadamente - a exemplo do número suficiente de leitos de Unidade de Terapia Intensiva (UTI) equipados para a COVID-19 - e a articulação eficiente entre as esferas federal, estadual e municipal de saúde. Tais fatores podem interferir diretamente na qualidade da assistência prestada à população e nas estimativas dos indicadores de saúde.

Assim, até que estimativas confiáveis de número de casos e óbitos estejam disponíveis no Brasil, recomenda-se evitar a utilização da letalidade como indicador para planejamento de ações em saúde a fim de conter a pandemia pelo novo coronavírus.

\section{Perspectivas futuras}

Em meados de outubro de 2020, é possível notar o surgimento recente de uma nova "onda" da epidemia de COVID-19 em alguns países da Europa: o número de casos diários já é maior do que o visto na "primeira onda", ocorrida entre março e abril. (OUR WORLD IN DATA, 2020)

No Brasil, nesse mesmo período, as medidas adotadas para conter o avanço da epidemia, principalmente em níveis estaduais e municipais, parecem não surtir o efeito esperado na curva epidêmica: existe uma tendência discreta de queda, mas que talvez não se sustente diante das medidas de reabertura econômica e da 
baixa testagem vistas atualmente no país. Assim, é muito provável que o Brasil também enfrente novas ondas da epidemia enquanto as medidas de mitigação, incluindo a testagem abrangente, não forem postas em prática de maneira mais eficaz, ou até que surja uma vacina. (KERR et al., 2020) Diante disso, a importância de indicadores de saúde de qualidade para o monitoramento apropriado da epidemia fica ainda mais evidente para controlar a epidemia no país.

\section{Conclusão}

O uso de indicadores em saúde é crucial para monitorar o avanço da pandemia da COVID-19, além de permitir comparações intra e entre países. No entanto, a variabilidade na composição populacional, nas estratégias de testagem - incluindo o número de testes realizados e a população-alvo -, nas definições de casos e óbitos, e na estrutura dos sistemas de saúde - em especial da vigilância epidemiológica - podem influenciar na qualidade desses indicadores, dificultando as comparações e sua aplicação na adoção de medidas de saúde pública para conter a epidemia. Assim, diante das peculiaridades de cada indicador, é fundamental aprimorar o monitoramento dos casos através da expansão da capacidade de testagem e do monitoramento de contatos, com vistas a identificar precocemente e limitar a ocorrência de novas ondas da doença.

\section{Referências}

ALFONSO III, F. Why some people of color say they won't wear homemade masks. CNN, Atlanta, 7 Apr. 2020. Disponível em: https://edition.cnn.com/2020/04/07/us/ face-masks-ethnicity-coronavirus-cdc-trnd/index.html. Acesso em: 27 out. 2020. 
BENDAVID, E. et al. COVID-19 Antibody Seroprevalence in Santa Clara County, California. MedRxiv, [s. I.], Apr. 2020. Disponível em: http://medrxiv.org/lookup/doi/ 10.1101/2020.04.14.20062463. Acesso em: 9 jun. 2020.

BETENSKY, R. A.; FENG, Y. Accounting for incomplete testing in the estimation of epidemic parameters. MedRxiv, [s. I.], 2020.

BOCCIA, S.; RICCIARDI, W.; IOANNIDIS, J. P. A. What Other Countries Can Learn From Italy During the COVID-19 Pandemic. JAMA Internal Medicine, Chicago, v. 180, n. 7, p. 927-928, July 2020.

BOLSONARO veta uso obrigatório de máscara no comércio, em escolas e em igrejas. Senado Noticias, Brasília, DF, 3 jul. 2020. Disponível em: https://www12. senado.leg.br/noticias/materias/2020/07/03/bolsonaro-veta-uso-obrigatorio-demascara-no-comercio-em-escolas-e-em-igrejas. Acesso em: 27 out. 2020.

BOSELEY, S. New data, new policy: why UK's coronavirus strategy changed. The Guardian, New York, 16 Mar. 2020a. Disponível em: https://www.theguardian. com/world/2020/mar/16/new-data-new-policy-why-uks-coronavirus-strategyhas-changed. Acesso em: 27 out. 2020.

BOSELEY, S. Test and trace: lessons from Hong Kong on avoiding a coronavirus lockdown. The Guardian, New York, 2020b. Disponível em: https://www. theguardian.com/world/2020/apr/17/test-trace-lessons-hong-kong-avoidingcoronavirus-lockdown. Acesso em: 9 jun. 2020.

BRASIL. Coronavírus Brasil. 2020a. Disponível em: https://covid.saude.gov.br/. Acesso em: 9 jun. 2020.

BRASIL. Lei ${ }^{\circ} 14.019$, de 2 de julho de 2020. Altera a Lei $n^{\circ} 13.979$, de 6 de fevereiro de 2020, para dispor sobre a obrigatoriedade do uso de máscaras de proteção individual para circulação em espaços públicos e privados acessíveis ao público, em vias públicas e em transportes públicos, sobre a adoção de medidas de assepsia de locais de acesso público, inclusive transportes públicos, e sobre a disponibilização de produtos saneantes aos usuários durante a vigência das medidas para enfrentamento da emergência de saúde pública de importância internacional decorrente da pandemia da Covid-19. Diário Oficial da União, Brasília, DF, 8 set. 2020b. Disponível em: http://www.planalto.gov.br/ccivil_03/_ ato2019-2022/2020/lei/L14019.htm. Acesso em: 27 out. 2020. 
BRASIL. Ministério da Saúde. Secretaria de Atenção Primária à Saúde. Protocolo de Manejo Clínico do Coronavírus (COVID-19) na Atenção Primária. Brasília, DF, abr. 2020c. Disponível em: https://portalarquivos.saude.gov.br/images/pdf/2020/ April/08/20200408-ProtocoloManejo-ver07.pdf. Acesso em: 18 maio 2020.

BRASIL. Ministério da Saúde. Secretaria de Ciência, Tecnologia, Inovação e Insumos Estratégicos em Saúde. Diretrizes para Diagnóstico e Tratamento da COVID-19 (MS) Brasil. Brasília, DF, 7 maio 2020d. Disponível em: https:// portaldeboaspraticas.iff.fiocruz.br/atencao-mulher/diretrizes-para-diagnostico-etratamento-da-covid-19-ms/. Acesso em: 8 jun. 2020.

BRASIL. Ministério da Saúde. Secretaria de Vigilância em Saúde. Guia de vigilância epidemiológica: emergência de saúde pública de importância nacional pela doença pelo Coronavírus 2019: vigilância integrada de síndromes respiratórias agudas doença pelo Coronavírus 2019, Influenza e outros vírus respiratórios. Brasília, DF, 2020e.

CARVALHO, A. I. de; BUSS, P. M. Determinantes sociais na saúde, na doença e na intervenção. In: GIOVANELLA, L. et al. (ed.). Políticas e Sistema de Saúde no Brasil. 2. ed. Rio de Janeiro: Editora Fiocruz, 2012. p. 121-142.

CARTÓRIOS registram aumento de 1.035\% nas mortes por síndrome respiratória. G1 - Jornal Nacional, Rio de Janeiro, 28 abr. 2020. Disponível em: https://g1.globo. com/jornal-nacional/noticia/2020/. Acesso em: 29 abr. 2020.

CHANG, B. B.-J.; CHIU, T.-Y. Ready for a long fight against the COVID-19 outbreak: an innovative model of tiered primary health care in Taiwan. BJGP Open, London, v. 4, n. 2, 2020.

CHENG, H.-Y.; LI, S.-Y.; YANG, C.-H. Initial rapid and proactive response for the COVID-19 outbreak - Taiwan's experience. Journal of the Formosan Medical Association, Taipei, v. 119, n. 4, p. 771-773, Apr. 2020.

COELHO, C. G. et al. Estratégias de testagem e indicadores de saúde. Salvador: Rede CoVida, 25 jun. 2020. Disponível em: https://covid19br.org/relatorios/estrategiasde-testagem-e-indicadores-de-saude/. Acesso em: 8 out. 2020.

COHEN, J.; KUPFERSCHMIDT, K. Countries test tactics in 'war' against COVID-19. Science, New York, v. 367, n. 6484, p. 1287-1288, Mar. 2020.

CONSELHO NACIONAL DE SECRETÁRIOS DE SAÚDE (Brasil). Painel CONASS COVID-19. Brasília, DF, 2020. Disponível em: http://www.conass.org.br/ painelconasscovid19/. Acesso em: 16 jun. 2020. 
COUSINS, S. New Zealand eliminates COVID-19. The Lancet, London, v. 395, n. 10235, p. 1474, May 2020.

GALINDO, J.; GORTÁZAR, N. G. A intensidade da pandemia que o Brasil (quase) não contabiliza. El País, [s. I.], 2020. Disponível em: https://brasil.elpais.com/ sociedade/2020-05-20/a-intensidade-da-pandemia-que-o-brasil-quase-naocontabiliza.html. Acesso em: 9 jun. 2020.

GIANICOLO, E. et al. Epidemiological measures in the context of the COVID-19 pandemic. Deutsches Ärzteblatt International, Berlin, v. 117, p. 336-342, May 2020.

GLOBAL PREPAREDNESS MONITORING BOARD. A World at Risk: Annual report on global preparednessfor health emergencies. Geneva: GPMB, 2019.

GORDIS, L. Medidas de ocorrência de doenças - II. Mortalidade. In: GORDIS, L. Epidemiologia. 5. ed. Rio de Janeiro: Thieme Revinter, 2017.

GRASSLY, N. et al. Report 16: Role of testing in COVID-19 control. London: Imperial College London, 2020.

GREWELLE, R.; DE LEO, G. Estimating the Global Infection Fatality Rate of COVID-19. MedRxiv, [s. I.], May 2020. Disponível em: http://medrxiv.org/ lookup/doi/10.1101/2020.05.11.20098780. Acesso em: 8 jun. 2020.

GUDBJARTSSON, D. F. et al. Spread of SARS-CoV-2 in the Icelandic Population. New England Journal of Medicine, Boston, Apr. 2020.

GUNIA, A. Why New Zealand's Coronavirus Elimination Strategy Is Unlikely to Work in Most Other Places. Time, [s. I.], 2020. Disponível em: https://time. com/5824042/new-zealand-coronavirus-elimination/. Acesso em: 15 jun. 2020.

HALLAL, P. et al. Remarkable variability in SARS-CoV-2 antibodies across Brazilian regions: nationwide serological household survey in 27 states. MedRxiv, [s. I.], May 2020. Disponível em: http://medrxiv.org/lookup/doi/10.1101/2020.05.30.2011 7531. Acesso em: 15 jun. 2020.

HALLAL, P. C. Worldwide differences in COVID-19-related mortality. Ciência \& Saúde Coletiva, Rio de Janeiro, v. 25, supl. 1, p. 2403-2410, June 2020.

IBRAHIM, N. K. Epidemiologic surveillance for controlling Covid-19 pandemic: types, challenges and implications. Journal of Infection and Public Health, Oxford, v. 13, n. 11, p. 1630-1638, Nov. 2020. 
INDIAN COUNCIL OF MEDICAL RESEARCH. Strategy for COVID19 testing in India. New Delhi, May 2020. Disponível em: https://www.icmr.gov.in/pdf/covid/strategy/ Testing_Strategy_v5_18052020.pdf. Acesso em: 8 jun. 2020.

IOANNIDIS, J. The infection fatality rate of COVID-19 inferred from seroprevalence data. MedRxiv, [s. I.], July 2020. Disponível em: http://medrxiv.org/lookup/doi/10.11 01/2020.05.13.20101253. Acesso em: 8 jun. 2020.

JOHNS HOPKINS CORONAVIRUS RESOURCE CENTER. Which U.S. States Meet Recommended Positivity Levels? [S. I.], May 2020. Disponível em: https://coronavirus. jhu.edu/testing/testing-positivity. Acesso em: 9 jun. 2020.

KANDEL, N. et al. Health security capacities in the context of COVID-19 outbreak: an analysis of International Health Regulations annual report data from 182 countries. The Lancet, London, v. 395, n. 10229, p. 1047-1053, Mar. 2020.

KERR, L. et al. COVID-19 no Nordeste brasileiro: sucessos e limitações nas respostas dos governos dos estados. Ciência \& Saúde Coletiva, Rio de Janeiro, v. 25, n. 2, p. 4099-4120, Oct. 2020.

KOREAN SOCIETY OF INFECTIOUS DISEASES et al. Report on the Epidemiological Features of Coronavirus Disease 2019 (COVID-19) Outbreak in the Republic of Korea from January 19 to March 2, 2020. Journal of Korean Medical Science, Seoul, v. 35, n. 10, 2020.

LACHMANN, A. et al. Correcting under-reported COVID-19 case numbers: estimating the true scale of the pandemic. MedRxiv, [s. I.], Apr. 2020.

Disponível em: http://medrxiv.org/lookup/doi/10.1101/2020.03.14.20036178. Acesso em: 8 jun. 2020.

LEGIDO-QUIGLEY, H. et al. Are high-performing health systems resilient against the COVID-19 epidemic? The Lancet, London, v. 395, n. 10227, p. 848-850, Mar. 2020.

LIU, Y. et al. The reproductive number of COVID-19 is higher compared to SARS coronavirus. Journal of Travel Medicine, Hamilton, v. 27, n. 2, Mar. 2020.

MARTÍNEZ-ANAYA, C.; RAMOS-CERVANTES, P.; VIDALTAMAYO, R. Coronavirus, diagnóstico y estrategias epidemiológicas contra COVID-19 en México. Educación Química, México, D.F., v. 31, n. 2, p. 12-22, 15 abr. 2020.

MAUGERI, A. et al. Estimation of Unreported Novel Coronavirus (SARS-CoV-2) Infections from Reported Deaths: A Susceptible-Exposed-Infectious-RecoveredDead Model. Journal of Clinical Medicine, Basel, v. 9, n. 5, p. 1350, 2020. 
MELLAN, T. et al. Report 21: Estimating COVID-19 cases and reproduction number in Brazil. London: Imperial College London, May 2020. Disponível em: http://spiral. imperial.ac.uk/handle/10044/1/78872. Acesso em: 9 jun. 2020.

MICHAELS, J. A.; STEVENSON, M. D. Explaining national differences in the mortality of Covid-19: individual patient simulation model to investigate the effects of testing policy and other factors on apparent mortality. MedRxiv, [s. I.], Apr. 2020. Disponível em: http://medrxiv.org/lookup/doi/10.1101/2020.04.02.20050633. Acesso em: 1 maio 2020.

MOTA, E.; KERR, L. R. F. S. Medidas de Ocorrência de Doenças, Agravos e Óbitos. In: ALMEIDA FILHO, N. de; BARRETO, M. L. (ed.). Epidemiologia e Saúde: fundamentos, métodos, aplicações. Rio de Janeiro: Guanabara Koogan, 2011. p. 95-117.

MUDANÇA em método da prefeitura faz Rio registrar menos 1.177 óbitos por Covid-19. G1 RIO, Rio de janeiro, 26 maio 2020. Disponível em: https://g1.globo. com/rj/rio-de-janeiro/noticia/2020/05/26/prefeitura-muda-metodo-e-rioregistra-menos-1177-obitos-por-covid-19.ghtml. Acesso em: 26 out. 2020.

MURRAY, C. J. Towards good practice for health statistics: lessons from the Millennium Development Goal health indicators. The Lancet, London, v. 369, n. 9564, p. 862-873, Mar. 2007.

NEW ZEALAND MINISTRY OF HEALTH. Case definition and testing guidance for COVID-19. Wellington, NZL, Nov. 2020. Disponível em: https://www.health.govt. nz/our-work/diseases-and-conditions/covid-19-novel-coronavirus/covid-19information-health-professionals/case-definition-and-testing-guidance-covid-19. Acesso em: 30 set. 2020.

ONDER, G.; REZZA, G.; BRUSAFERRO, S. Case-fatality rate and characteristics of patients dying in relation to COVID-19 in Italy. JAMA, Chicago, v. 323, n. 18, p. $1775-1776,2020$.

OUR WORLD IN DATA. Coronavirus (COVID-19) Cases - Statistics and Research. 2020. Disponível em: https://ourworldindata.org/covid-cases. Acesso em: 26 set. 2020.

PORTA, M. S. (ed.). A dictionary of epidemiology. 5th ed. Oxford: Oxford University Press, 2008.

RAJGOR, D. D. et al. The many estimates of the COVID-19 case fatality rate. The Lancet Infectious Diseases, New York, v. 20, n. 7, p. 776-777, July 2020. 
REALITY CHECK TEAM. Did China test a whole city in 10 days? BBC News, [s. I.], 8 June 2020. Disponível em: https://www.bbc.com/news/world-asiachina-52651651. Acesso em: 15 jun. 2020.

RED ARGENTINA PÚBLICA DE EVALUACIÓN DE TECNOLOGÍAS SANITARIAS. Informe Rápido de Evaluación de Tecnología Sanitaria (IRETS): diferentes tipos de tests y estrategias diagnósticas en el contexto de pandemia por COVID-19. 22 abr. 2020. Disponível em: http://www.femeba.org.ar/ documentos/download/4792-diferentes-tipos-de-tests-y-estrategiasdiagnosticas-en-el-contexto-de-pandemia-por-covid-19-redarets-04-2020.pdf. Acesso em: 8 jun. 2020.

RICHTERICH, P. Severe underestimation of COVID-19 case numbers: effect of epidemic growth rate and test restrictions. MedRxiv, [s. I.], Apr. 2020.

RUDNICKI, W. R.; PILISZEK, R. Estimate of Covid-19 prevalence using imperfect data. MedRxiv, [s. I.], Apr. 2020.

SCHNEIDER, E. C. Failing the Test - The Tragic Data Gap Undermining the U.S. Pandemic Response. New England Journal of Medicine, Boston, v. 38, n. 4, p. 299-302., july 2020.

SHAH, J. et al. COVID-19: the current situation in Afghanistan. The Lancet Global Health, London, v. 8, n. 6, p. e771-e772, jun. 2020.

SPYCHALSKI, P.; BŁAŻYŃSKA-SPYCHALSKA, A.; KOBIELA, J. Estimating case fatality rates of COVID-19. The Lancet Infectious Diseases, New York, v. 20, n. 7, p. $774-775,2020$.

STAFFORD, N. Covid-19: Why Germany's case fatality rate seems so low. BMJ, London, 7 Apr. 2020.

TANNE, J. H. Coronavirus pandemic stirs fight over abortion rights in US. BMJ, London, v. 369, 30 abr. 2020.

UNDELA, K.; GUDI, S. K. Assumptions for disparities in case-fatality rates of coronavirus disease (COVID-19) across the globe. European Review for Medical and Pharmacological Sciences, Rome, v. 24, n. 9, p. 5180-5182, May 2020.

UNIVERSIDADE FEDERAL DE PELOTAS. Resultado da 2 a etapa da Pesquisa sobre Covid-19. Pelotas, 2020. Disponível em: http://ccs2.ufpel.edu.br/wp/2020/04/29/ resultado-da-2a-etapa-da-pesquisa-sobre-covid-19/. Acesso em: 29 abr. 2020. 
WANG, C. J.; NG, C. Y.; BROOK, R. H. Response to COVID-19 in Taiwan: Big Data Analytics, New Technology, and Proactive Testing. JAMA, Chicago, v. 323, n. 14, p. 1341-1342, Apr. 2020.

WORLD HEALTH ORGANIZATION - WHO. Public health criteria to adjust public health and social measures in the context of COVID-19. 12 May 2020a.

Disponível em: https://www.who.int/publications-detail-redirect/public-healthcriteria-to-adjust-public-health-and-social-measures-in-the-context-of-covid-19. Acesso em: 30 set. 2020.

WORLD HEALTH ORGANIZATION - WHO. Report of the WHO-China Joint Mission on Coronavirus Disease 2019 (COVID-19). 24 Feb. 2020b. Disponível em: https:// www.who.int/docs/default-source/coronaviruse/who-china-joint-mission-oncovid-19-final-report.pdf. Acesso em: 15 jun. 2020.

WORLDOMETERS. COVID-19 Coronavirus Pandemic. 2020. Disponível em: https:// www.worldometers.info/coronavirus/. Acesso em: 16 jul. 2020.

WU, S. L. et al. Substantial underestimation of SARS-CoV-2 infection in the United States due to incomplete testing and imperfect test accuracy. MedRxiv, [s. I.] , May 2020. Disponível em: http://medrxiv.org/lookup/doi/10.1101/2020.05.12.200 91744. Acesso em: 8 jun. 2020. 